\title{
Bovine TB, Badger Culling and Applied Ethics: Utilitarianism, Animal Welfare and Rights
}

\author{
Robert Garner ${ }^{1}$
}

Accepted: 30 July 2017/Published online: 11 August 2017

(C) The Author(s) 2017. This article is an open access publication

\begin{abstract}
Applying competing ethical theories to the issue of bovine TB and badger culling can throw light on the validity of the policy options. Utilitarianism is, superficially at least, an attractive option. However, the aggregative principle is problematic and this is well illustrated in the case of bovine TB and badger culling. Such is the variety and strength of interests to be considered that it is not at all clear which course of action will maximise utility. In addition, it may be that the full range of consequences can never be known with any degree of accuracy. An alternative option is to revert to an animal welfare ethic. This has the effect of cutting down the moral complexities involved in a discussion of bovine TB and badger culling, since, providing it is done humanely, killing badgers is not an ethical issue, and even the infliction of suffering on them is permissible providing it serves a significant human benefit. The animal welfare ethic, however, is normatively inadequate because it exaggerates the ethical importance of personhood. Because of this, it allows us to justify killing badgers, and might even justify the infliction of considerable suffering if by so doing there is a good chance that economic benefits will accrue. As a result, a deontological position, where animals are accorded the protection of rights, seems a much more promising alternative to utilitarianism. The adoption of any variety of animal rights would render badger culling morally illegitimate.
\end{abstract}

As the articles in this special issue of the journal demonstrate, applying competing ethical theories to the issue of bovine TB and badger culling can not only guide us in our choice of policy options, but can also throw light on the validity of the ethical

Robert Garner

rwg2@leicester.ac.uk

1 School of History, Politics and International Relations, University of Leicester, University Road, Leicester LE1 7RH, UK 
theories themselves. In my view, the articles reveal, in particular, the problems inherent in a utilitarian account, and suggest that we need to look elsewhere for the most appropriate ethical theory.

The advantage of the Animal Welfare Impact Assessment, of course, is that it does allow for the inclusion of animal interests within policy making. Clearly, too, such an inclusion is justified on utilitarian grounds. As was pointed out, the attractiveness of utilitarianism from an animal ethics perspective is that the benchmark of moral standing is sentience, or the capacity to experience pleasure or pain. Since the conventional view now is that nonhuman animals, along with humans, are sentient, it means they can be included as part of the utilitarian calculus. Moreover, central to utilitarianism is the equality principle. Individuals are to count equally. This requires, in Singer's words, that 'the interests of every being affected by an action are to be taken into account and given the same weight as the like interests of any other' (Singer 1989: 77).

The problems start, however, when it also recognised that utilitarianism (or at least act utilitarianism) adopts an aggregative principle. That is, when judging the ethical permissibility of a particular action, the requirement is that we weigh up the total amount of happiness, or pleasure or preferences (depending on the particular type of utilitarianism adopted) produced, or likely to be produced.

One problem here is that it is by no means clear that we can ever reach, on utilitarian grounds, a determinate decision on the rightness or wrongness of a particular action. This is illustrated well by the case study under discussion here. For, as the article admirable shows, there are a huge number of interests to consider when judging what policy is going to maximise utility. Moreover, it is not just the number of people (or animals) which has to be measured, but the intensity of the preferences held. So, utilitarianism is not simply a matter of counting preferences. Bentham usually referred to utilitarianism's goal as the greatest happiness (which allows for measuring the intensity of pleasure and pain) rather than the greatest happiness of the greatest number (which can be interpreted as a head counting exercise). It would seem accurate to say, for instance, that the impact of bovine TB on consumers is not likely to be as great as the impact on a farmer whose herd is infected. Nevertheless, there are severe difficulties in quantifying the difference in any objective sense.

In addition, utilitarianism often faces huge problems in determining what the total impacts of an action are likely to be. This is well-illustrated in the case of the bovine TB and badgers issue. In short, the extent to which badger culling is effective in eradicating bovine TB is a matter of huge dispute. I was struck by how many of the statements in the article trying to quantify the impact of different policy options were shrouded in a significant degree of uncertainty. Early on it is stated that a number of 'baseline assumptions' are made about the impact of badger control methods. It is further stated that the 'impacts on farmers' of badger culling 'are uncertain due to the question of whether there would in reality be a significant net financial benefit' and that there is 'considerable uncertainty about whether implementation of the policy can be successful', and that the larger timeframe we adopt will mean an increase in 'assumptions and uncertainty'. The article concludes by arguing that badger vaccination is the 'optimal policy option from a utilitarian 
perspective'. This conclusion is a reasonable one (given that it will help to eradicate bovine TB without the need to kill or inflict severe suffering on badgers which, in turn, will satisfy the preference of animal activists and the majority of public opinion). However, this conclusion is only valid, of course, if badger vaccination actually works and, it appears to me, there is considerable doubt about this.

A response to my critique of utilitarianism might be that the doubts and uncertainties raised simply reflect the indeterminate nature of moral judgements. Bentham may have wanted to be the 'Newton of the Moral Sciences' but he offered us a moral theory that can never, and should never, ape the accuracy of natural science. This, however, overlooks another problem with the aggregative principle inherent in utilitarianism. It does not, intuitively, appear to be very just, and this stems from the fact that, for utilitarians, justice is a secondary concern. Justice is subordinate to the primary concern with maximising utility.

In short, then, utilitarianism neglects the individual. Its aggregative character results in allowing 'some people to be treated as less than equals, as a means to other people's ends' (Rowlands 2009: 42). In other words, the way that humans and animals are treated in utilitarianism is not a product of the characteristics they possess as individuals 'but of the effects of their treatment on others' (56). This would still be the case even if there is a valid claim for saying that this or that way animals are treated is, in fact, illegitimate morally on utilitarian grounds. In short, utilitarianism does not give people what they are due. Indeed, it distorts 'the concept of equal consideration beyond recognition' (Regan 1984: 213). A classic example of this is that unrefined act utilitarianism would justify the punishment of the innocent if by so doing utility is maximised.

So, where do we turn if we reject utilitarianism as a guide to the issue under discussion in this special edition? One answer is to revert to an animal welfare ethic. It is important, before we proceed any further, to recognise that animal welfare, as an ethic, is significantly different from utilitarianism as it has been described above. A consideration of Peter Singer's position is instructive here (Singer 1989). Singer is an exponent of utilitarianism, the heir of Bentham. He suggests that we ought to treat like interests alike (the equal consideration of interests), and since at least some animals are sentient it is morally illegitimate to prioritize human interests in not suffering on all occasions. This, Singer argues, is the conclusion Bentham ought to have arrived at, but failed to for whatever reason.

Some scholars have-mistakenly — argued that Singer's utilitarianism is equivalent to an animal welfare position (Anderson 2004: 227; Francione and Garner 2010: 6-13). This is partly because Singer emphasizes the moral importance of sentience and partly because he does not base his theory on the according of rights to animals. In this sense, he is a welfarist in that he is a consequentialist, concerned to maximize welfare, as opposed to an advocate of a deontological position which argues that individuals should be protected even if by so doing welfare is not maximized.

However, if we combine the moral importance of sentience with the equality principle in utilitarianism (that the like interests of sentient beings ought to be considered equally) then it can be seen that Singer's position is very different from an animal welfare ethic. This is because the central feature of the animal welfare 
ethic is an insistence that humans are morally superior to animals, but that, since animals have some moral worth, we are not entitled to inflict suffering on them if the human benefit thereby resulting is not necessary. The principle of unnecessary suffering, therefore, can be invoked if the level of suffering inflicted on an animal outweighs the benefits likely to be gained by humans. The political philosopher Robert Nozick (1974: 35-42) provides a concise but admirably effective definition of animal welfare when he writes that it constitutes 'utilitarianism for animals, Kantianism for people.' Sacrificing the interests of animals for the aggregative welfare, then, is permissible providing that the benefit is significant enough, but treating humans in the same way is prohibited whatever the benefits that might accrue from so doing.

The effect of adopting an animal welfare ethic is to cut down the moral complexities. In the case of bovine $\mathrm{TB}$ and badgers, for instance, the significant interests of humans - whether they be farmers or consumers or the general publicmust take precedence over the interests of badgers (and indeed cattle). The interests that badgers have in not suffering must be taken into account, but even these interests can be overridden if the human benefit is thought significant enough. What is more, killing badgers (provided it is done humanely) does not need to be of any ethical concern, whether or not there is proof that they are the primary cause (or one of the causes) of bovine TB.

It is probably the acceptance of this animal welfare ethic that explains why many do not regard badger culling as an important ethical issue. It also illustrates, from my perspective, why the animal welfare ethic is normatively inadequate. To see how this is so, consider the grounds on which human moral superiority is justified. This is usually based on the identification of cognitive capacities-rationality, free will, self-consciousness - that humans have (collected together under the label of personhood) which animals do not. Now, whilst it might be true that personhood does morally justify differential treatment (it might be said, for instance, that a human's life is more valuable than an animal's), it does not follow, however, that we are therefore entitled to override any interests animals have in order to defend any of the interests humans have, at least without an additional argument explaining why we are entitled to do this.

In particular, if humans and animals are capable of suffering in an equivalent manner (as utilitarians claim) then why is this capacity of animals downgraded on the grounds that humans also possess the characteristics of personhood? In other words, what has personhood got to do with suffering? James Rachels (1990: 186) sets out the illogicality of this argument nicely. He asks us to consider the case of cosmetics testing on animals-say, for example, putting chemicals in rabbits' eyes to test the safety of a new shampoo. He writes, 'To say that rabbits may be treated in this way, but humans may not, because humans are rational agents, is comparable to saying that one law school applicant may be accepted, and another rejected because one has a broken arm while the other has an infection'.

What I am arguing here, then, is that the fact that humans are persons and animals are not cannot justify the whole range of differences between our treatment of humans and animals that the animal welfare ethic wants it to do. To put it simply, torturing an animal is wrong because it hurts. Here, the fact that the animal does not 
have the characteristics of personhood would seem to be irrelevant. As Rachels (2004: 167) points out then: 'Autonomy and self-consciousness are not ethical superqualities that entitle the bearer to every possible kind of favourable treatment'.

It would seem then that animal welfare is deeply flawed as a guide as to how we should consider the debate about bovine TB and badgers. It allows us to justify killing badgers (whether or not we can be certain that they are responsible for causing bovine TB) and might even justify the infliction of considerable suffering if by so doing there is a good chance that economic benefits will accrue to farmers, consumers and taxpayers as a result.

The normative flaws of the animal welfare ethic mean that a deontological position, where animals are accorded the protection of rights, seems a much more promising alternative to utilitarianism. As the article in the special edition makes clear, the adoption of any variety of animal rights (excluding perhaps my non-ideal theory of animal rights) means that badger culling is morally prohibited. Only where infected badgers represent a serious threat to human health, which they are not, would this conclusion be in any doubt.

Only when we have to choose between badger vaccination and a do-nothing policy might different versions of animal rights come into play. The article correctly distinguishes between different animal rights positions, most notably contrasting the traditional will or choice theory of rights associated with Regan and the interestbased theory associated with Cochrane and Garner. However, this contrast, in practice, does not have much relevance to the issue at hand because vaccination is ruled out according to both versions of animal rights on the grounds that to do so involves the infliction of suffering.

A distinction that might have more purchase is between negative and positive rights. Traditionally, animal rights philosophers such as Regan have adopted a position of non-interference. Humans, that is, should leave animals alone. The value of Donaldson and Kymlicka's approach is that they have recognised that this position is intuitively odd because it does not take into account the so-called 'laissez faire' intuition whereby it is permissible morally to leave wild animals to their fate whilst it is unacceptable to neglect domesticated animals in the same way, irrespective of the cognitive capacities of the animals concerned (see also Palmer 2010). Utilizing a relational ethic, as Donaldson and Kymlicka (2011) do, can justify leaving wild animals alone, and therefore avoid the need to get embroiled in debates about whether we ought to intervene to prevent the suffering of wild animals not least when this suffering is caused by other animals, as in predation. By contrast, domesticated animals, because of the relationship we have with them, can expect us to intervene in a positive fashion to prevent and alleviate suffering, at least when it is not against our interests to do so.

Some animal rights philosophers, however, have argued that, in certain circumstances at least, there is a moral case for intervening to protect the interests of wild animals and this is precisely what happens in practice. Humans do, for instance, sometimes intervene to prevent predation (as in the case of trying to prevent domestic cats from killing birds), and do seek to prevent other humans from preying on wild animals as in the case of whaling (Cochrane 2012; Horta 2012). The relevance of this for the badger, of course, is that the existence of TB might justify 
intervening to impose vaccination. Even these grounds for intervention, in the interests of badgers, would not seem to be justified, however, because badgers seem to have a remarkable toleration to the infection which rarely proves fatal to them.

Open Access This article is distributed under the terms of the Creative Commons Attribution 4.0 International License (http://creativecommons.org/licenses/by/4.0/), which permits unrestricted use, distribution, and reproduction in any medium, provided you give appropriate credit to the original author(s) and the source, provide a link to the Creative Commons license, and indicate if changes were made.

\section{References}

Anderson, E. (2004). Animal rights and the values of nonhuman life. In C. Sunstein \& M. Nussbaum (Eds.), Animal rights: Current debates and new directions (pp. 277-298). New York: Oxford University Press.

Cochrane, A. (2012). Cosmozoopolis: The case against group-differentiated animal rights. Law, Ethics and Philosophy, 1. http://leap-journal.com/archives/LEAP1-Alasdair-Cochrane.pdf.

Donaldson, S., \& Kymlicka, W. (2011). Zoopolis: A political theory of animal rights. New York: Oxford University Press.

Francione, G., \& Garner, R. (2010). The animal rights debate: Abolition or regulation. New York: Columbia University Press.

Horta, O. (2012). Zoopolis, intervention, and the state of nature. Law, Ethics and Philosophy, 1, 113-125. Nozick, R. (1974). Anarchy, state and utopia. Oxford: Basil Blackwell.

Palmer, C. (2010). Animal ethics in context. New York: Columbia University Press.

Rachels, J. (1990). Created from animals: The moral implications of darwinism. Oxford: Oxford University Press.

Rachels, J. (2004). The basic argument for vegetarianism. In S. Sapontzis (Ed.), Food for thought: The debate over eating meat (pp. 70-80). New York: Prometheus Books.

Regan, T. (1984). The case for animal rights. London: Routledge.

Rowlands, M. (2009). Animal rights: Moral theory and practice. Basingstoke: Palgrave.

Singer, P. (1989). All animals are equal. In T. Regan \& P. Singer (Eds.), Animal rights and human obligations (2nd ed., pp. 73-86). Englewood Cliffs, NJ: Prentice Hall. 